\title{
Sexual selection in Estrildid finches, with further review of the evolution of nesting material holding display in relation to cooperative parental nesting
}

\author{
MASAYO SOMA ${ }^{11}$
}

\begin{abstract}
Estrildid finches (family: Estrildidae) are characterised by great intraspecific and intersexual variations in sexual traits, which include courtship song, dance and ornamental colourations of plumage. These features are expected to help us answer some questions about the evolution of sexual signals: (1) why multiple ornaments evolve in socially monogamous species; and (2) why, in certain species, males and females share identical sexual traits. To discuss these, first, I briefly review the past phylogenetic comparative studies of Estrildids and show that the three sexual traits evolved independently. Secondly, I focus on one behavioural component of the courtship dance, nesting material holding display, and test the idea that the display evolved as a signal of nest building ability using phylogenetic comparative approaches. The results showed that males exhibited nesting material holding displays in species where males tend to work harder to prepare nests, which indicates that parental cooperation plays a role in the evolution of sexual signals.
\end{abstract}

Key words : courtship display, Estrildid finches, nest-building, sexual selection, songbird

\section{Introduction: The multiple sexual traits of Estrildid finches}

Estrildid finches (family: Estrildidae) are gaining considerable popularity in ethology, comparative cognitive science, neurobehavioral biology, and their related disciplines in recent decades, mostly due to the intensive birdsong studies on the two 'star' species in the taxonomic group: the zebra finch (Taeniopygia guttata), and the Bengalese finch (Lonchura striata var. domesctica). Previous studies have contributed to our understanding of both the proximate and ultimate factors that explain

1) Behavioral Neurobiology Group, Department of Biology, Faculty of Science, Hokkaido University

Hokkaido University, Kita 10 Nishi 8, Kita-ku Sapporo, Hokkaido 060-0810, Japan

Corresponding author: MASAYO SOMA

E-mail: masayo.soma@sci.hokudai.ac.jp

J-STAGE Advance Published Date: June 12, 2018. doi: $10.2502 /$ janip. 68.2 .2 the evolution of birdsong, i.e. mechanisms of vocal (song) learning, and sexual selection on birdsong (Zann, 1996; Brainard \& Doupe, 2002; Riebel, 2009; Okanoya, 2004a; Okanoya, 2004b). In contrast with male song, however, other intriguing features of Estrildid finches tend to be neglected.

Estrildid finches represent a taxonomic group of songbirds that consists of over 130 species, characterised by multiple sexual traits and their interspecific and intersexual variations. They have at least three major sexual signals that play roles in mate choice: courtship songs, visual displays (referred to as courtship dance hereafter), and ornamental colourations of plumage. For example, when male zebra finches sing courtship songs towards potential mates nearby, they simultaneously perform a courtship dance, containing waltz-like pivoting motions to approach females (Morris, 1954; Kunkel, 1959; Williams, 2001; Ullrich, Norton, \& Scharff, 2016). In 
addition, males, but not females, of the zebra finch have orange cheeks, chest stripes and flank spots, some of which are known to be both related with individual quality or conditions, and subject to female preference (Swaddle \& Cuthill, 1994; Zann, 1996; Birkhead, Fletcher, \& Pellatt, 1999; Bolund, Martin, Kempenaers, \& Forstmeier, 2010). Just like the zebra finch, all males of the Estrildid species are assumed to possess courtship-related song and dance, although some lack sexual dichromatism in plumage colouration (Goodwin, 1982). Generally, intense sexual selection promotes the evolution of exaggerated sexual traits or multiple ornamentations (Møller \& Pomiankowski, 1993; Candolin, 2003), yet the question remains as to why multiple sexual signals evolved in a socially monogamous species like Estrildid finches. Furthermore, what evolutionary factors explain the amongspecies variations they present?

The above-mentioned three aspects of sexual signalling (song, dance, and plumage characteristics) can be shared between the sexes in some Estrildid species (cf. Soma \& Garamszegi, 2015), which provides a potential key in solving the mystery of the evolution of female ornamentation (Amundsen, 2000; Kraaijeveld, Kraaijeveld-Smit, \& Komdeur, 2007; Clutton-Brock, 2009). As shown in Table 1, Estrildid finches show great interspecific variations regarding the presence and ab- sence of female sexual signalling, implying that each trait evolved independently (for more details, see Soma \& Garamszegi, 2015).

\section{The evolution of courtship dance in relation to other sexual traits}

Following the progression of comprehensive understanding of sexual signals in Estrildid finches, phylogenetic comparative approaches have started to be adopted (Gomes, Sorenson, \& Cardoso, 2016; Gomes at al., 2017; Soma \& Garamszegi, 2015, 2018). Previous studies aimed to explore what selective forces promoted the evolution of each sexual trait (song, dance, and plumage characteristics) in each sex, and to further investigate whether these traits show correlated evolution. This was conducted by comparing trait expressions among species, whilst controlling for phylogenetic relationships. The degree of elaboration in one trait is expected to be associated with those of the others, if the traits are not independent; for example, when they have the same signalling functions, and/or are under the control of the same pleiotropic mechanisms, such as hormones, genes or neurotransmitters. It is also possible that there is a tradeoff between two traits, when it is too costly to maintain them both (Badyaev, Hill, \& Weckwort, 2002; Shutler, 2011). Alternatively, each sexual signal may evolve independently of the others under the influence of different

Table 1. Examples of sexual differences in three sexual traits (song, dance, and plumage characteristics).

\begin{tabular}{|c|c|c|c|c|c|}
\hline & Species & $\begin{array}{c}\text { Female } \\
\text { song }\end{array}$ & $\begin{array}{c}\text { Female } \\
\text { dance }\end{array}$ & $\begin{array}{l}\text { Sexual } \\
\text { dichromatism } \\
\text { in plumage }\end{array}$ & References \\
\hline Zebra finch & Taeniopygia guttata & no & no & yes & 1 \\
\hline $\begin{array}{l}\text { Bengalese finch } \\
\text { White-rumped munica }\end{array}$ & $\begin{array}{l}\text { Lonchura striata var. domesctica } \\
\text { Lonchura striata }\end{array}$ & no & no & no & $2-4$ \\
\hline Java sparrow & Lonchura oryzivora & no & yes & no & $4-7$ \\
\hline $\begin{array}{l}\text { Blue-capped cordon-bleu } \\
\text { Red-cheeked cordon-bleu }\end{array}$ & $\begin{array}{l}\text { Uraeginthus cyanocephalus } \\
\text { Uraeginthus bengalus }\end{array}$ & yes & yes & yes & $8-12$ \\
\hline
\end{tabular}

1: Zann, 1996; 2: Okanoya, 2004a; 3: Okanoya, 2004b; 4: Restall, 1996; 5: Kagawa \& Soma, 2013;

6: Ota \& Soma, 2014; 7: Soma \& Iwama, 2017; 8: Gahr \& Güttinger, 1986; 9: Geberzahn \& Gahr, 2011;

10: Geberzahn \& Gahr, 2013; 11: Ota, Gahr, \& Soma, 2015; 12: Ota, Gahr, \& Soma, 2017 
aspects of reproductive ecology or life history.

Considering the behavioural features of Estrildid courtship, it is plausible that courtship dance may well be associated with both song and plumage (Figure 1). As courtship song and dance are performed at the same time, in a well-coordinated manner, at least in some species (e.g. Ota, Gahr, \& Soma, 2015, 2017; Ullrich, Norton, \& Scharff, 2016), they are assumed to function for the same purpose. As courtship dance and plumage colouration are both visual signals, motions are likely to affect the animal's perception of the visual signals (Zahavi, 1978; Hasson, 1991). However, against these predictions, the outcomes from the previous phylogenetic comparative studies showed little evidence for joint evolution of the three sexual signals (song, dance, and plumage characteristics), except for a positive correlation between dance and the conspicuousness of plumage patterns (Soma \& Garamszegi, 2018; Figure 1). When we measure the degree

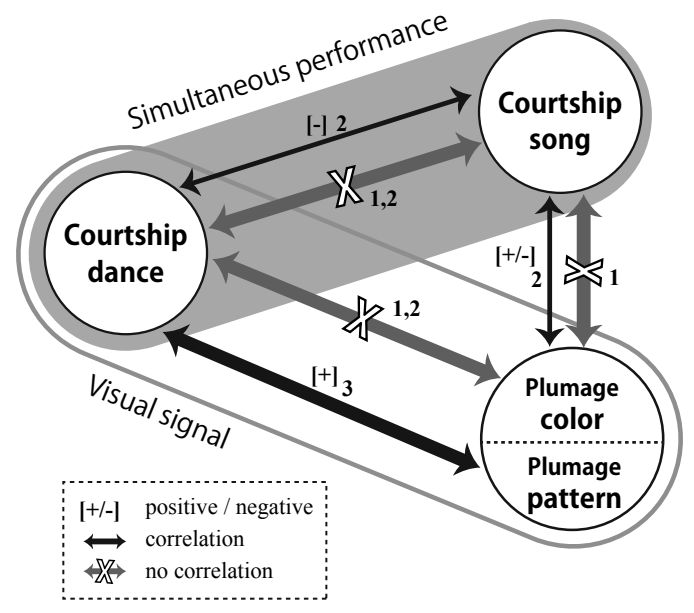

Figure 1. Schematic view of the evolutionary relationships between courtship dance and the other two sexual signals (plumage and song), revealed by the previous phylogenetic comparative studies of Estrildid finches (1: Soma \& Garamszegi, 2015; 2: Gomes, Funghi, Soma, et al. 2017; 3: Soma \& Garamszegi, 2018). The results were mixed when multiple measures were taken for song or plumage elaboration (2: Gomes, Funghi, Soma, et al. 2017), but generally indicated a lack of consistent and strong correlation. of elaboration of dance based on the repertoire of motions that constitutes dance displays (see the next section for details), males of the species with more elaborate dances do not necessarily have more ornamented plumage colourations (Soma \& Garamszegi, 2015) or complex songs (Gomes et al., 2017; Figure 1). In addition, there were no clear associations between song and plumage (Soma \& Garamszegi, 2015; Gomes et al. 2017; Figure 1).

Overall, the available evidence so far suggests that the multiple sexual signals of Estrildid species evolved independently, in response to different selection pressures (Gomes, Sorenson, \& Cardoso, 2016; Gomes et al., 2017; Soma \& Garamszegi, 2015, 2018). In fact, Gomes, Sorenson, and Cardoso (2016) found that gregariousness and higher investment in reproduction are related to ornamental colourations, whereas larger bodied species tended to have more complex dances (Soma \& Garamszegi, 2015). Furthermore, the presence of intra-specific brood parasitism was shown to be related to the evolution of visual signals (i.e. dance and plumage patterns) (Soma \& Garamszegi, 2015, 2018). In short, we are yet to see the whole picture of the evolution of sexual signals in this taxonomic group, however socio-ecological factors, especially those concerned with breeding, most likely hold a key to understanding it.

What is already clear for Estrildid finches is that the elaborations of both plumage and dance are positively correlated between males and females within the species (Soma \& Garamszegi, 2015, 2018). Unfortunately, intersexual song correlations remain unknown because acoustic features of female song are not documented except for a couple of species, where males and females sing quite similar songs (Gahr \& Güttinger, 1986; Geberzahn \& Gahr, 2011, 2013). I can infer two functional reasons why Estrildids show intersexual correlation for plumage and dance. Firstly, mutual mate choice may have promoted the evolution of sexual signals in both sexes, though it is also possible that 
the same signalling trait is used for intrasexual competition in each sex (review in Tobias, Montgomerie, \& Lyon, 2012; see also Crowhurst et al., 2012; Zanollo et al., 2014). Secondly, as shown in the Java sparrow (Lonchura oryzivora), in which duet dancing is a key predictor of mating success (Soma \& Iwama, 2017), behavioural displays that allow interactive communication between males and females can contribute to pairformation, and possibly pair-bonding as well (cf. Hall, 2004; Hall \& Magrath, 2007; Ręk \& Magrath, 2016; Takeda \& Kutsukake, 2018).

\section{The ethological meaning of courtship dance}

Song and plumage have been well-studied as targets of sexual selection in birds (Hill \& McGraw, 2006; Catchpole \& Slater, 2008), however, in comparison, dance (or visual display) has had less attention and therefore leaves room for further investigations. Estrildid finches perform quite simple courtship dances. They are usually composed of several basic components of body motions, which our previous study (Soma \& Garamszegi, 2015) organised into 9 categories: (1) bobbing, i.e., up and down movement of head; (2) horizontal body movement, such as turning, changing body angle or pivoting; (3) wing movement; (4) tail movement, such as angling or spreading the tail, or tail quivering; (5) erection of body feathers; (6) hopping or stepping; (7) holding nesting material in the bill; (8) bill wiping, i.e., rubbing the bill on the perch; and (9) opening the mouth or showing the tongue. Interspecific and intersexual variations of Estrildid dance are characterised by the presence/absence of these components. Evolutionary loss or gain of each dance component might be caused by the differences in selective force: repertoire size of dance components might increase/decrease depending on species ecology, just like song repertoire size increased under intense sexual selection pressure (MacDougall-Shackleton, 1997). Alternatively, it is also possible that each dance component codes different information respectively.
Past ethological literature has provided detailed descriptions of each dance component and tried to infer their meanings and evolutionary origins (Kunkel, 1967; Morris, 1954, 1957, 1958; Goodwin, 1982; Baptista et al., 1999). For example, showing an openmouth apparently resembles with the begging behaviour of chicks (Goodwin, 1982; Baptista et al., 1999), which makes sense in the view of the sensory trap hypothesis that juvenilelike behaviour in males can facilitate female response (Hasegawa et al., 2013). It would be natural to think that holding nesting material in the bill is related with nest preparatory behaviours (Goodwin, 1982) (see also the next section). In addition, bill-wiping, which is shown during courtship in non-Estrildid species as well, has been recently proposed to function as an olfactory display (Whittaker et al., 2015). However, the other components of Estrildid dance are hard to interpret semantically. Perhaps some components are just for demonstrating one's physical condition, especially when they include acrobatic motions (e.g. tap-dancing in cordon-bleus: Ota, Gahr, \& Soma, 2015), or for grabbing the receiver's attention.

\section{Interspecific relationships between nest building and nesting material holding display}

In an effort to integrate the ethological and evolutionary views of courtship dance in Estrildid finches, here, I would like to shed light on one specific dance component: nesting material holding (Figure 2a). This behaviour is so characteristic of this taxonomic group's mating rituals, courtship itself is sometimes referred to as 'straw display' or 'stem display'. According to the recent research (De Silva et al., 2017), Estrildid finches are closely related, phylogenetically, to weaverbirds (family: Ploceidae), a family known for intricately woven nests that are typically made by males and subject to female mate choice (Collias \& Collias, 1984; see also Quader, 2005). In general, Estrildid finches do not seem to be as good at weaving as weaverbirds, but, presumably, 

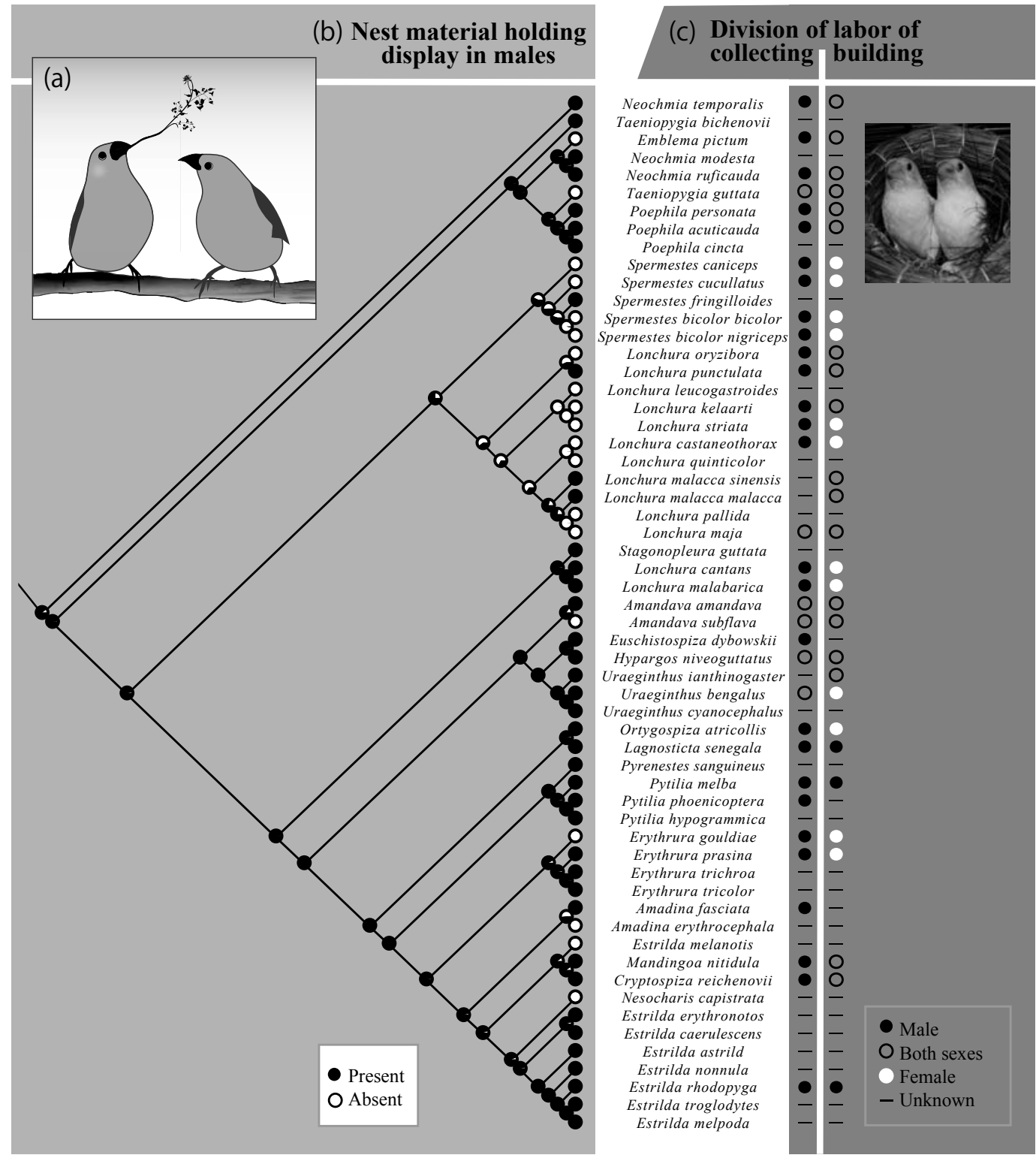

Figure 2. Nesting material holding display of Estrildid finches (a). Ancestral reconstruction of nesting material holding display in males (b), in relation to parental cooperation of nesting material collecting and nest building (c).

holding nesting materials in the bill during courtship can function as an advertisement an individual's ability to collect and carry nesting materials.

Unlike the weaverbird's many polygynous species, Estrildid finches are socially monogamous, and males and females cooperate to prepare nests. Typically, males collect nesting materials, such as straws or grass, for females to sit in and build nests, however there is wide interspecific variation in the way they cooperate. If nesting material holding display functions as an indicator of nesting ability, the presence/absence of the display would be evolutionarily correlated with two things; firstly, the pattern of 
division of labour of nesting between the sexes, and secondly, the amount of materials the nest requires. Specifically, I predicted as follows:

(1) Male nesting material holding display will be present in species where males take on a considerable proportion of nest making, whereas both sexes might display if they need to cooperate to prepare nests.

(2) Nesting material holding display may disappear in species that use other species nests or cavities/holes to avoid labourious collection of nesting materials.

To test these ideas, I ran small phylogenetic comparative analyses, based on the phylogenetic data and presence/absence of nesting material holding displays in each species that had been previously studied (for details see Soma \& Garamszegi, 2015). Note that the definition of the presence of 'nesting material holding display' is that birds hold nesting materials during courtship, regardless of whether they keep on holding them whilst singing. In addition, I checked how much males and females participate in nest preparations (i.e. collection of nesting materials and nest building) and scored them as follows: 2: males do, 1: both sexes do, or 0 : females do, based on the relevant literature (Goodwin, 1982; Payne, 2010). As some species were reported to use multiple types of nests (Goodwin, 1982; Payne, 2010), the nest types of each species were scored based on whether grass nests were used or not, and whether cavities or other species nests were used or not, relying on the literary descriptions. Using phylogenetic generalized leastsquare (PGLS) regressions (see detailed methods in Soma \& Garamszegi, 2015), I tested the effects of division of nesting-based labour between the sexes, and nest types on the presence of nesting material holding displays in males and females.

I found that males present nesting material holding displays in species where

Table 2. Phylogenetic multiple regression models relating division of labour of nesting and nest type with the presence of nesting material holding display in males (a) and females (b). To consider intersexual correlation, the presence of female/male straw-holding display was also entered as an explanatory variable in male/female models respectively. * indicates statistical significance $(P<0.05)$.

(a) Male nesting material holding display

\begin{tabular}{|c|c|c|c|c|}
\hline & Coefficient & SE & $t$ & $P$ \\
\hline (Intercept) & -0.096 & 0.784 & -0.12 & 0.904 \\
\hline Presence of female nesting material holding display & 0.001 & 0.007 & 0.12 & 0.909 \\
\hline \multicolumn{5}{|l|}{ Division of labour } \\
\hline Collecting nesting materials & 0.445 & 0.157 & 2.84 & 0.009 \\
\hline Building nest (2: male, 1 : both, 0 : female) & 0.480 & 0.132 & 3.64 & 0.001 \\
\hline \multicolumn{5}{|l|}{ Nest type } \\
\hline Grass nest $\quad(0$ : absent, 1: present $)$ & -0.391 & 0.639 & -0.61 & 0.546 \\
\hline Use of cavity or other species nest ( 0 : absent, 1 : present $)$ & -0.010 & 0.064 & -0.16 & 0.878 \\
\hline
\end{tabular}

(b) Female nesting material holding display

\begin{tabular}{|c|c|c|c|c|}
\hline & Coefficient & SE & $t$ & $P$ \\
\hline (Intercept) & 0.367 & 0.742 & 0.49 & 0.625 \\
\hline Presence of male nesting material holding display & 0.416 & 0.193 & 2.16 & 0.042 \\
\hline \multicolumn{5}{|l|}{ Division of labour } \\
\hline Collecting nesting materials (2: male, 1 : both, $0:$ female) & -0.330 & 0.219 & -1.50 & 0.146 \\
\hline Building nest (2: male, 1 : both, 0 : female) & -0.113 & 0.151 & -0.75 & 0.461 \\
\hline \multicolumn{5}{|l|}{ Nest type } \\
\hline Grass nest (0: absent, 1: present) & 0.335 & 0.524 & 0.64 & 0.529 \\
\hline Use of cavity or other species nest (0: absent, 1 : present) & -0.011 & 0.186 & -0.06 & 0.955 \\
\hline
\end{tabular}


males tend to work more for preparing nests, but that nest type had no influence on it (Table 2, Figure 2). In contrast, there were no statistically significant effects of nesting division of labour and nest type on female display, but females tended to display when males displayed also (Table $2 \mathrm{~b}$ ).

These findings suggest that how much males work for preparing nests is an illustrative factor in the evolution of nesting material holding display, which is compatible with the idea that the display may function as an indicator of nesting ability. In contrast, in females, intersexual correlation alone accounts for the evolution of the display. This is presumably because females exhibit courtship dancing with the aim of mutual communication with their partners (e.g. duet dancing; Soma \& Iwama, 2017) rather than demonstrating nesting ability. As available information for analyses was limited (Figure 2c), these findings should be seen as preliminary. Moreover, the direct association between the display and the ability of nesting material carrying should be tested to support this view.

\section{Progressing understanding of courtship as male-female communication}

Sexual selection and parental investment are interlinked. For instance, one recent avian-wide phylogenetic comparative study has revealed negative associations between them; males, under intense sexual selection pressure, exert increasing amounts of effort to attract females. This results in decreased investment in rearing of the offspring, overall lowering parental cooperation. (Remeš et al., 2015). Similarly, when comparing cuckoo species with and without parental care (i.e. brood parasites or not), parasitic species were shown to be more ornamented (Hasegawa \& Arai, 2018). However, another phylogenetic comparative study on passerine species proposed that nest-building activity itself could serve as a sexually selected display (Soler, Møller, \& Soler, 1998). These previous findings might look contradictory, but were probably influenced by the heterogeneity in the breeding ecologies of the targeted species. Contrasting biparental-care species with those that totally lack paternal care (e.g. brood parasites, lek breeding) can highlight the negative associations between paternal investment and ornamentation. However, insight can be gained from the positive correlation between sexual signalling and parental investment (i.e. nest preparation), shown in the previous section; interspecific comparisons focusing on all monogamous and pairbonding species may reveal the possibility that female mate choice is based on 'good father' traits.

To conclude, understanding male-female communication is key in understanding the evolution of sexual signals, especially in socially monogamous species like Estrildid finches. Multiple sexual signals (i.e. song, dance, and plumage characteristics) that can be shared between both sexes of Estrildids have only just begun to be understood evolutionarily, or ecologically. However, based on the available evidence, I am sure that at least some components of said signals play roles in mutual communication in pairing partners. To further understanding of sexual signals such as these, I expect future empirical studies to reveal their breeding ecology, such as the pair-bonding periods and its effect on reproductive success, or the occurrence of extra-pair mating. In addition, more information on female song would be sure to advance this area of research.

\section{Acknowledgements}

I thank Honor Scarlett for checking the manuscript.

\section{References}

Amundsen, T. 2000 Why are female birds ornamented? Trends in Ecology and Evolution, 15, 149-155.

Badyaev, A. V., Hill, G. E., \& Weckwort, B. V. 2002 Species divergence in sexually selected traits: increase in song elaboration is related to decrease in plumage 
ornamentation in finches. Evolution, 56, 412-419.

Baptista, L. F., Lawson, R., Visser, L., \& Bell, D. A. 1999 Relationships of some manikins and waxbills in the estrildidae. Journal of Ornithology, 140, 179-192.

Birkhead, T. R., Fletcher, F., \& Pellatt, E. J. 1999 Nestling diet, secondary sexual traits and fitness in the zebra finch. Proceedings of the Royal Society of London B, 266, 385-390.

Bolund, E., Martin, K., Kempenaers, B., \& Forstmeier, W. 2010 Inbreeding depression of sexually selected traits and attractiveness in the zebra finch. Animal Behaviour, 79, 947-955.

Brainard, M. S., \& Doupe, A. J. 2002 What songbirds teach us about learning. Nature, 417, 351-358.

Candolin, U. 2003 The use of multiple cues in mate choice. Biological Reviews, 78, 575-595.

Catchpole, C. K., \& Slater, P. J. B. 2008 Bird Song, Biological Themes and Variations, 2nd ed. Cambridge University Press.

Collias, N. E., \& Collias, E. C. 1984 Nest Building and Bird Behaviour. Princeton University Press.

Crowhurst, C. J., Zanollo, V., Griggio, M., Robertson, J., \& Kleindorfer, S. 2012. White flank spots signal feeding dominance in female diamond firetails, Stagonopleura guttata. Ethology, 118, 63-75.

De Silva, T. N., Townsend Peterson, A., Bates, J. M., Fernando, S. W., \& Girard, M. G. 2017 Phylogenetic relationships of weaverbirds (Aves: Ploceidae): A first robust phylogeny based on mitochondrial and nuclear markers. Molecular Phylogenetics and Evolution, 109, 21-32.

Gahr, M., \& Güttinger, H. R. 1986 Functional aspects of singing in male and female Uraeginthus bengalus (Estrildidae). Ethology, 72, 123-131.

Geberzahn, N., \& Gahr, M. 2011 Undirected (solitary) birdsong in female and male blue-capped cordon-bleus (Uraeginthus cyanocephalus) and its endocrine correlates. PLoS ONE, 6, e26485.
Geberzahn, N., \& Gahr, M. 2013 Song Learning in male and female (Uraeginthus cyanocephalus), a tropical songbird species. Journal of Comparative Psychology, 127, 352-364.

Gomes, A. C. R., Funghi, C., Soma, M., Sorenson, M. D., \& Cardoso, G. C. 2017 Multimodal signalling in estrildid finches: song, dance and colour are associated with different ecological and life-history traits. Journal of Evolutionary Biology, 30, 1336-1346.

Gomes, A. C. R., Sorenson, M. D., \& Cardoso, G. C. 2016 Speciation is associated with changing ornamentation rather than stronger sexual selection. Evolution, 70, 2823-2838.

Goodwin, D. 1982 Estrildid Finches of the World. Cornell University Press.

Hall, M. L. 2004 A review of hypotheses for the functions of avian duetting. Behavior al Ecology and Sociobiology, 55, 415-430.

Hall, M. L., \& Magrath, R. D. 2007 Temporal coordination signals coalition quality. Current Biology, 17, R406-R407.

Hasegawa, M., \& Arai, E. 2018 Differential visual ornamentation between brood parasitic and parental cuckoos. Journal of Evolutionary Biology, 31, 446-456.

Hasegawa, M., Arai, E., Watanebe, M., \& Nakamura, M. 2013 Male nestling-like courtship calls attract female barn swallows, Hirundo rustica gutturalis. Animal Behaviour, 86, 949-953.

Hasson, O. 1991 Sexual displays as amplifiers: Practical examples with an emphasis on feather decorations. Behavioral Ecology, 2, 189-197.

Hill, G. E., McGraw, K. J. 2006 Bird Color ation. Harvard University Press.

Kagawa, H., \& Soma, M. 2013 Song performance and elaboration as potential indicators of male quality in Java sparrows. Behavioural Processes, 99, 138144.

Kraaijeveld, K., Kraaijeveld-Smit, F. J. L., \& Komdeur, J. 2007 The evolution of mutual ornamentation. Animal Behaviour, 74, 657-677. 
Kunkel, P. 1959 Zum Verhalten einiger Prachtfinken (Estrilidinae). Zeitschrift für Tierpsychologie, 16, 302-350.

Kunkel, P. 1967 Displays facilitating sociability in waxbills of the genera Estrilda and Lagonosticta (fam. Estrildidae). Behaviour, 29, 237-261.

MacDougall-Shackleton, S. A. 1997 Sexual selection and the evolution of song repertoires. Current Ornithology, 14, 81-124.

Møller, A. P., \& Pomiankowski, A. 1993 Why have birds got multiple sexual ornaments? Behavioral Ecology and Sociobiolo$g y, 32,167-176$.

Morris, D. 1954 The reproductive behaviour of the Zebra Finch (Poephila guttata), with special reference to pseudofemale behaviour and displacement activities. Behaviour, 6, 271-322.

Morris, D. 1957 The reproductive behaviour of the bronze mannakin, Lonchura cucullata. Behaviour, 11, 156-201.

Morris, D. 1958 The comparative ethology of grassfinches (Erythrurae) and mannikins (Amadinae). Journal of Zoology, 131, 389439.

Okanoya, K. 2004a. Song syntax in Bengalese finches: proximate and ultimate analyses. Advances in the Study of Behavior, 34, 297-346.

Okanoya, K. 2004b. The Bengalese finch: a window on the behavioral neurobiology of birdsong syntax. Annals of the New York Academy of Sciences, 1016, 724-735.

Ota, N., Gahr, M., \& Soma, M. 2015 Tap dancing birds: the multimodal mutual courtship display of males and females in a socially monogamous songbird. Scientific Reports, 5, 16614.

Ota, N., Gahr, M., \& Soma, M. 2017 Songbird tap dancing produces non-vocal sounds. Bioacoustics, 26, 161-168.

Ota, N., \& Soma, M. 2014 Age-dependent song changes in a closed-ended vocal learner: elevation of song performance after song crystallization. Journal of Avian Biology, 45, 566-573.

Payne, R. B. 2010 Family Estrildidae (waxbills) in Handbook of the Birds of the World 15, (eds J. del Hoyo, A. Elliott, \& D. A. Christie). Lynx. pp.234-377.

Quader, S. 2005 Elaborate nests in a weaverbird: a role for female choice? Ethology, 111, 1073-1088.

Ręk, P., \& Magrath, R. D. 2016 Multimodal duetting in magpie-larks: how do vocal and visual components contribute to a cooperative signal's function? Animal Behaviour, 117, 35-42.

Remeš, V., Freckleton, R. P., Tökölyi, J., Liker, A., \& Székely, T. 2015 The evolution of parental cooperation in birds. Proceedings of the National Academy of Sciences, 112, 13603-13608.

Restall, R. 1996 Munias and Mannikins. Pica Press.

Riebel, K. 2009 Song and female mate choice in zebra finches: a review. Advances in the Study of Behavior, 40, 197-238.

Shutler, D. 2011 Sexual selection: when to expect trade-offs. Biology Letters, 7, 101104.

Soler, J. J., Møller, A. P., \& Soler, M. 1998 Nest building, sexual selection and parental investment. Evolutionary Ecology, 12, 427-441.

Soma, M., \& Garamszegi, L. Z. 2015 Evolution of courtship display in Estrildid finches: dance in relation to female song and plumage ornamentation. Frontiers in Ecology and Evolution, 3, 4.

Soma, M., \& Garamszegi, L. Z. 2018 Evolution of patterned plumage as a sexual signal in estrildid finches. Behavioral Ecology, 29, 676-685.

Soma, M., \& Iwama, M. 2017 Mating success follows duet dancing in the Java sparrow. PLOS ONE, 12, e0172655.

Swaddle, J. P., \& Cuthill, I. C. 1994 Female zebra finches prefer males with symmetric chest plumage. Proceedings of the Royal Society of London B, 258, 267-271.

Takeda, K. F., \& Kutsukake, N. 2018 Complexity of mutual communication in animals exemplified by paired dances in the red-crowned crane. Japanese Journal of Animal Psychology (in press).

Tobias, J. A., Montgomerie, R., Lyon, B. E. 
2012 The evolution of female ornaments and weaponry: social selection, sexual selection and ecological competition. Philosophical Transactions of the Royal Society B, 367, 2274-2293.

Ullrich, R., Norton, P., \& Scharff, C. 2016 Waltzing Taeniopygia: integration of courtship song and dance in the domesticated Australian zebra finch. Animal Behaviour, 112, 285-300.

Whittaker, D. J., Reichard, D. G., Drouilly, M., Battle, K., \& Ziegenfus, C. 2015 Avian olfactory displays: a hypothesis for the function of bill-wiping in a social context. Behavioral Ecology and Sociobiology, 69, 159-167.
Williams, H. 2001 Choreography of song, dance and beak movements in the zebra finch (Taeniopygia guttata). Journal of Experimental Biology, 204, 3497-3506.

Zahavi, A. 1978 Decorative patterns and the evolution of art. New Scientist, 19, 182184.

Zann, R. A. 1996 The Zebra Finch. Oxford University Press.

Zanollo, V., Griggio, M., Robertson, J., \& Kleindorfer, S. 2014 Assortative pairings in diamond firetails (Stagonopleura gutta$t a)$ are not the result of mutual mate choice for an ornament. Ethology, 120, 951-964.

(2018. 3.28 受稿, 2018. 5.24 受理) 